\title{
Pengembangan Lembar Kerja Peserta Didik (LKPD) Berbasis Problem Based Learning (PBL) dalam Meningkatkan Kemampuan Berpikir Kritis Siswa Pada Mata Pelajaran Sosiologi di SMA Negeri 1 Payakumbuh
}

\author{
Sisra Elfina ${ }^{1}$, Ike Sylvia ${ }^{2}$ \\ ${ }_{1,2}^{1}$ Universitas Negeri Padang \\ Email: sisra.elfina@gmail.com, $\underline{\text { ikesylvia@fis.unp.ac.id }}$
}

\begin{abstract}
Abstrak
Penelitian ini dilakukan dengan tujuan untuk (1) mengetahui keterlaksanaan penggunaan LKPD berbasis PBL dalam meningkatkan kemampuan berpikir kritis peserta didik (2) mengetahui peningkatan kemampuan berpikir kritis peserta didik. Penelitian pengembangan LKPD ini menggunakan model 4D yang meliputi tahap define (pendefinisian), design (perancangan), develop (pengembangan), dan disseminate (penyebarluasan). Subjek dalam penelitian ini adalah 33 peserta didik kelas XI IPS 3 SMA N 1 Payakumbuh. Instrumen yang digunakan dalam penelitian ini meliputi lembar validasi media LKPD, lembar validasi materi LKPD, angket respon/ partikalitas peserta didik terhadap LKPD, serta soal pre-test dan post-test peserta didik. Data keterlaksanaan pembelajaran dianalisis dengan menggunakan pedoman kriteria penilaian dalam bentuk persentase. Data yang diperoleh dari soal pre-test dan post-test dianalisis dengan menggunakan T-hitung $>$ dari Ttabel. Uji t-test berkorelasi dilakukan untuk mengetahui signifikansi perkembangan tingkat berpikir kritis siswa. Hasil penelitian menunjukkan LKPD dirasa cukup efektif dalam meningkatkan kemampuan berpikir kritis siswa, karena memberikan pengaruh yang signifikan dilihat dari uji t-test.
\end{abstract}

Kata kunci: Kemampuan Berpikir Kritis Siswa, LKPD, PBL

\section{Abstract}

This study aims to (1) determine the use of PBL-based LKPD in improving students 'critical thinking skills (2) find out the increase in students' critical thinking skills. This LKPD development study uses the $4 D$ model which includes the stages of defining, designing, developing, and disseminating. The subjects in this study were 33 students of class XI IPS 3 of SMA N 1 Payakumbuh. The instruments used in this study included the LKPD validation sheet, students 'response / particulate questionnaire to LKPD, as well as students' pre-test and post-test questions. Data on learning achievement was analyzed using guideline assessment criteria in the form of a percentage. Data obtained from the pretest-posttest questions were analyzed using $T$-count $>$ from $T$ table. Correlated $t$-test was conducted to determine the significance of the growth of students' critical thinking levels. The results showed that LKPD was considered to be quite effective in improving students' critical thinking skills, because it had a significant effect on the T-test.

Keywords: LKPD, PBL, Students' Critical Thinking Ability

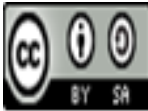

Received: May 2, 2020 Revised: August 17, 2020 Accepted: August 18, 2020 


\section{Pendahuluan}

Salah satu faktor yang menjadi penentu dalam melahirkan generasi bangsa dimasa depan adalah dengan melalui pendidikan. Jenjang pendidikan yang ditempuh meliputi Sekolah Dasar (SD), Sekolah Menengah Pertama (SMP), Sekolah Menengah Atas (SMA) hingga pada jenjang perguruan tinggi. Namun, dalam penelitian ini peneliti mengkhususkan pada jenjang pendidikan Sekolah Menengah Atas (SMA). BNSP (2010) menyebutkan bahwa pendidikan nasional abad 21 merupakan salah satu upaya dalam mewujudkan masyarakat bangsa Indonesia yang sejahtera dan bahagia baik secara lokal maupun global. Untuk itu, ada kecakapan yang harus dimiliki oleh setiap individu agar tetap bersaing dan diperhitungkan dalam kehidupan pada abad ke-2, yaitu, (1) critical thinking and problem solving, (2) collaboration, (3) good communication, (4) creative and innovative thinking skill, (5) social responsibility, (6) work ethic. (Sylvia et al., 2019). Berbagai macam upaya dilakukan salah satunya adalah implementasi kurikulum 2013 serta pendekatan pengajaran yang tepat juga dibutuhkan guna melatih kemampuan berpikir tingkat tinggi siswa khususnya pada kemampuan kritis siswa. Upaya inovasi pendidikan juga telah menjadi prioritas pemerintah, diantaranya adalah penyempurnaan kurikulum (Sylvia, 2013).

Menurut Sardiman (Sadirman, 1996), berpikir adalah suatu aktivitas mental untuk dapat merumuskan sesuatu menarik kesimpulan. Sedangkan menurut Ngalim Purwanto(Purwanto, 2007) mengatakan bahwa berpikir merupakan satu kegiatan aktif pribadi manusia yang menghasilkan penemuan terarah.

Menurut Santrock berpikir kritis merupakan pemikiran yang reflektif dan produktif. Jensen dalam (Sylvia, 2019) mempunyai pendapat bahwa berpikir kritis adalah sebuah proses mental yang efektif dan handal. Sedangkan Cece Wijaya (2010: 72) dalam penelitian (Sylvia, 2019) juga mengungkapkan gagasannya mengenai kemampuan berpikir kritis, yaitu suatu kegiatan yang menganalisis ide dan gagasan yang spesifik dan lebih tajam serta mengembangkannya menjadi lebih sempurna. Berpikir kritis tentu mempunyai tujuan, menurut Sapriya (2011: 87) dalam skripsi (Nurhayati, 2014), tujuan berpikir kritis adalah menguji suatu pendapat atau ide, hingga melakukan pertimbangan berdasarkan pendapat yang diajukan, dan dapat dipertanggungjawabkan. Meningkatkan kemampuan berpikir kritis tentu membutuhkan variasi saat proses belajar mengajar berlangsung, salah satunya menggunakan media pembelajaran seperti LKPD.

Namun, LKPD yang banyak beredar dan dipakai di sekolah saat sekarang ini bersifat umum dan hanya berisi ringkasan materi saja. Hal ini dapat menjadi penyebab kurangnya ketertarikan peserta didik terhadap LKPD dan akan berdampak pada kurangnya mengasah kemampuan berpikir kritis pada peserta didik. Hal lain yang menyebabkan kurangnya ketertarikan peserta didik terhadap LKPD adalah pengemasan materi yang cenderung kurang bermakna sehingga menyebabkan peserta didik hanya sebatas mengahafal konsep tanpa memahami makna dari konsep tersebut. Sebagai media pembelajaran, LKPD mempunyai beberapa komponen atau unsur yang menjadikannya layak digunakan sebagai media pembelajaran, hal ini dipertegas oleh (Wulandari, 2013) yang mengatakan bahwa peran LKPD sangat penting dalam pelaksanaan proses pembelajaran karena mampu meningkatkan aktivitas peserta didik dalam proses pembelajaran. Maka dari itu unsur-unsur LKPD menurut (Sari, 2011) diantaranya judul, petunjuk belajar, indikator pembelajaran, informasi pendukung, langkah kerja, dan penilaian. Hal ini juga dipertegas dengan lebih rinci oleh (Widyantini, 2013) yang menyebutkan unsur-unsur LKPD yaitu judul, mata pelajaran, semester, tempat, petunjuk belajar, kompetensi yang akan dicapai, indikator pembelajaran, informasi pendukung, alat dan bahan dalam mengerjakan LKPD, langkah kerja, dan penilaian. Selain LKPD yang akan dikembangkan tentu diperlukan perangkat penunjang lainnya.

Menurut Ibrahim dalam (Trianto, 2009) perangkat yang digunakan saat proses pembelajaran berlangsung disebut dengan perangkat pembelajaran. Perangkat-perangkat 
pembelajaran yang diperlukan dan digunakan saat proses belajar mengajar diantaranya: silabus, RPP, LKS, Instrumen Evaluasi atau Tes Hasil Belajar (THB), media pembelajaran salah satunya LKPD, serta buku ajar atau buku pegangan siswa. Pernyataan ini sinkron dengan pendapat Andi Prastowo(Prastowo, 2014) yaitu sebuah bahan ajar cetak yang berupa lembar-lembar kertas berisi materi, ringkasan dan petunjukpelaksanaan tugas yang akan dikerjakan dan mengacu pada $\mathrm{KD}$ yang harus dicapai. Dalam penelitian ini peneliti menggunakan model pembelajaran Problem Based Learning, dimana menurut (Ibrhim, 2013) penilaian kegiatan pembelajaran dapat diambil melalui pengamatan, lalu kemampuan peserta didik dalam merumuskan pertanyaan, serta upaya peserta didik dalam menciptakan solusi untuk memecahkan permasalahan. Model pembelajaran berdasarkan masalah mulai dikenalkan sejak zaman John Dewey. Pembelajaran ini mulai diangkat karena dilihat secara umum pembelajaran berbasis masalah disajikan dengan permasalahan yang autentik sehingga memberikan kemudahan pada peserta didik untuk melakukan penyelidikan (Rumini, 1998). Menurut Etherington, M. B (Craig, 2015) PBL (problem based learning) merupakan sebuah metode yang berpusat pada peserta didik dengan melibatkan cara belajar melalui pemecahan masalah.

\section{Metode Penelitian}

Dalam penelitian ini, peneliti menggunakan metode penelitian Research and Development atau R\&D. Menurut (Sugiyono, 2009) penelitian R\&D adalah sebuah penelitian yang digunakan untuk menghasilkan produk tertentu lalu diuji cobaka untuk mengetahui keefektifan produk tersebut. Hal ini juga diungkapkan oleh Nana Syaodih Sukmadinata (Sukmadinata, 2005) bahwa penelitian dengan metode ini merupakan suatu proses untuk membuat dan mengembangkan sebuah produk atau media pembelajaran atau bisa juga menyempurnakan produk yang sudah ada. Berdasarkan kedua pengertian para ahli di atas, dapat disimpulkan bahwa metode penelitian R\&D ialah suatu metode penelitian yang menghasilkan sebuah produk atau media ajar yang akan diuji cobakan kepada peserta didik, baik itu produk baru yang dihasilkan, maupun produk lama yang disempurnakan. Metode penelitian R\&D ini juga sering digunakan dalam dunia pendidikan karena produk-produk yang dihasilkan melalui penelitian R\&D diharapkan dapat meningkatkan produktifitas dan efektifitas pendidikan salah satunya yaitu dengan menghasilkan lulusan yang berkualitas. Produk pendidikan tersebut dapat berupa kurikulum yang spesifik dengan keperluan pendidikan, metode mengajar, media, buku panduan atau buku ajar, modul pembelajaran, model pembelajaran, sistem evaluasi peembelajaran, dan lainnya yang berhubungan dengan pembelajaran.

Desain penelitian ini menggunakan metode Research and Development (R\&D) yang digunakan ialah model 4D Thiagarajan, et al.(Thiagarajan, 1774) mengemukakan 4D yang terdiri dari empat tahapan yaitu tahap pendefinisian (Define), tahap perencanaan (Design), tahap pengembangan (Develop), dan tahap penyebaran (Disseminate). Tahap akhirpada penelitian ini adalah penyebaran (Disseminate) yang dilakukan secara terbatas. Dalam penelitian ini ada tiga angket yang bagikan dan dikembangkan, yaitu angket validasi media, angket validasi materi dan angket partikalitas siswa yang bertujuan untuk melihat validitas media, materi dan keefektifan produk untuk diujicobakan dalam proses pembelajaran. Angket pertama diberikan kepada ahli media, untuk melihat validitas media yang telah dikembangkan. Angket kedua diberikan kepada ahli materi, hal ini juga melihat validitas materi atau kesesuaian materi yang dikembangkan dalam media LKPD. Angket ketiga diberikan kepada peserta didik yang dijadikan sampel yaitu peserta didik kelas XI IPS 3 SMA N 1 Payakumbuh yang belajar materi integrasi sosial sesuai dengan LKPD yang peneliti kembangkan untuk mengukur keefektifan LKPD sebagai media pembelajaran sosiologi.

Teknik analisis data menggunakan rumus analisis validitas dengan mencari rata-rata empiris dengan menggunakan rumus: 


$$
x=\frac{\sum x}{\mathrm{n}}
$$

Keterangan:

$$
\begin{aligned}
& \mathrm{x}=\text { rata }- \text { rata } \\
& \sum x=\text { jumlah nilai } \\
& \mathrm{n} \quad=\text { jumlah responden }
\end{aligned}
$$

Untuk menghitung persentase dari tiap- tiap subvariabel dengan rumus:

$$
P(s)=\frac{s}{N} \mathrm{X} 100 \%
$$

Keterangan:

$$
\begin{array}{ll}
P(s) & =\text { persentase sub variable } \\
\mathrm{S} & =\text { Jumlah skor tiap sub variable } \\
\mathrm{N} & =\text { Jumlah skor maksimun }
\end{array}
$$

Adapun kriteria interpretasi yang peneliti gunakan adalah sebagai berikut:

Tabel 1. Kriteria Interpretasi

\begin{tabular}{lcc}
\hline No. & Presentase & Kriteria \\
\hline 1. & $81-100 \%$ & Sangat baik \\
\hline 2. & $61-80 \%$ & Baik \\
\hline 3. & $41-60 \%$ & Cukup baik \\
\hline 4. & $21-40 \%$ & Kurang baik \\
\hline 5. & $0-20 \%$ & Sangat tidak baik \\
\hline
\end{tabular}

Sumber: Ridwan (Ridwan, 2012),

Selanjutnya untuk melihat kepraktisan media komik peneliti menggunakan rumus:

$$
x=\frac{\sum x}{\mathrm{n}}
$$

Menurut Ridwan (2012:13) untuk melihat kepraktisan media komik pada mata pelajaran sosiologi bisa dianalisis dengan criteria sebagai berikut:

$$
\begin{aligned}
& 5=\text { Sangat Praktis } \\
& 4=\text { Praktis } \\
& 3=\text { Cukup Praktis } \\
& 2=\text { Kurang Praktis } \\
& 1=\text { Tidak Praktis }
\end{aligned}
$$

Kemudian rumus yang digunakan untuk untuk melihat validitas media peneliti menggunakan rumus:

$$
\mathrm{t}=\frac{M d}{\sqrt{\frac{\sum x^{2} d}{N(N-1)}}}
$$

\section{Hasil dan Pembahasan}

\section{Tahap Pendefinisian (define)}

Pada tahap perencanaan ini peneliti terlebih dahulu melakukan analisis kurikulum dan karakteristik peserta didik. Pemilihan materi integrasi sosial sebagai materi yang dikembangkan 
media pembelajarannya dalam bentuk Lembar Kerja Peserta Didik (LKPD) didasarkan menurunnya solidaritas dalam kehidupan manusia Indonesia saat ini, terutama di kalangan peserta didik, menuntut pentingnya penyadaran pada peserta didik bahwa dalam kehidupan bermasyarakat perlu dijaga solidaritas sosial dan harmonisasi sosial. Salah satu cara agar peserta didik mengetahui pentingnya solodaritas dan harmonisasi sosial bagi keberlanjutan kehidupannya adalah dengan mempelajari materi integrasi sosial termasuk didalamnya definisi, bentuk, faktro pendorong, serta faktor penyebab terjadinya integrasi sosial. Selain itu guru juga secara tidak langsung sudah menanamkan nilai karakter kepada peserta didiknya. Dengan dibekali kecakapan ini sebagai tambahan kecakapan akademik peserta didik akan terbantu memecahkan permasalahan individual dan sosial yang dihadapi dalam kehidupan di lingkungannya. (Sylvia et al., 2019). Peneliti juga melakukan analisis karakteristik peserta didik sebelum membuat rencana pengembangan LKPD. Menurut studi pendahuluan yang telah dilakukan pada Juli Desember 2019 di kelas XI IPS 3 SMAN 1 Payakumbuh, peserta didik cenderung hanya menggunakan buku sumber yang tidak mengakomodir semua peserta didik. Peserta didik tidak pernah menggunakan media pembelajaran yang bervariasi dalam hal meningkatkan kemampuan berpikir kritis dan tidak memiliki keinginan lebih dalam memahami materi pembelajaran khususnya materi integrasi sosial.

\section{Tahap Perencanaan (design)}

Pada tahap ini peneliti mulai menyusun format LKPD tahap awal serta membuat lembar validasi yang akan diberikan dalam menilai kelayakan dan keefektifan LKPD yang akan dikembangkan. Adapun lembar validasi yang dibuat oleh peneliti adalah lembar validasi media, lembar validasi materi, dan lembar angket partikalitas yang akan diberikan pada peserta didik.

\section{Tahap Pengembangan (develop)}

\section{Validasi Media}

Pada tahap ini LKPD divalidasi oleh dua orang validator ahli media yaitu Bapak Junaidi dan Bapak Erianjoni, M.Si yang merupakan dosen Sosiologi Universitas Negeri Padang. Hasil validasi angket media LKPD yang peneliti kembangkan berdasarkan hasil instrumen validasi yang telah ditelaah oleh pakar adalah sebagi berikut:

\section{Tabel 2. Hasil Validasi Penilaian Media}

\begin{tabular}{|c|c|c|c|c|}
\hline \multirow[t]{2}{*}{ No } & \multirow[t]{2}{*}{ Aspek } & \multirow[t]{2}{*}{ Indikator } & \multicolumn{2}{|c|}{ Skor } \\
\hline & & & Ahli 1 & Ahli 2 \\
\hline 1. & Cover & $\begin{array}{l}\text { LKPD disajikan dengan cover atau sampul yang } \\
\text { menarik. }\end{array}$ & 1 & 4 \\
\hline \multicolumn{5}{|c|}{ Jumlah: $\mathbf{5 0 \%}$} \\
\hline 2. & $\begin{array}{l}\text { Kesesuaian LKPD } \\
\text { dengan Materi }\end{array}$ & $\begin{array}{l}\text { LKPD disajikan sesuai dengan materi yang } \\
\text { diajarkan. }\end{array}$ & 1 & 5 \\
\hline \multicolumn{5}{|c|}{ Jumlah: $60 \%$} \\
\hline 3. & Sintak LKPD & $\begin{array}{l}\text { LKPD disajikan dengan menggunakan langkah } \\
\text { kerja yang jelas sehingga membantu siswa } \\
\text { mengoptimalkan waktu pembelajaran. }\end{array}$ & 2 & 5 \\
\hline \multicolumn{5}{|c|}{ Jumlah: 70\% } \\
\hline 4. & Soal LKPD & $\begin{array}{l}\text { LKPD disajikan lengkap dengan soal yang } \\
\text { menguji tingkat kemapuan berpikir kritis siswa. }\end{array}$ & 1 & 3 \\
\hline
\end{tabular}

Jumlah: $40 \%$

Sumber: Data primer 2020

Berdasarkan hasil validasi media oleh pakar, pada aspek cover yang memiliki 1 indikator mendapat rata-rata 2,5 dengan nilai validasi $50 \%$, sedangkan untuk aspek kesesuaian LKPD dengan materi yang memiliki 1 indikator memperoleh rata-rata 3 dengan nilai validasi $60 \%$, 
aspek selanjutnya adalah aspek sintak LKPD dengan 1 indikator mendapat rata-rata 3,5 dengan nilai validasi $70 \%$, sedangkan aspek soal LKPD yang memiliki 1 indikator mendapat rata-rata 2 dengan nilai validasi $40 \%$. Secara keseluruhan aspek media dari validator mendapat rata-rata 2,75 dengan nilai validasi 55\% yang artinya berada pada kriteria "cukup baik".

\section{Validasi Materi}

Pada tahap ini validasi materi LKPD oleh pakar yaitu Ibu Yarlen Nelfina, S.Pd yang merupakan guru Sosiologi di SMA Negeri 1 Payakumbuh Hasil validasi angket materi LKPD yang peneliti kembangkan berdasarkan hasil instrumen validasi yang telah ditelaah oleh pakar adalah sebagi berikut :

\section{Tabel 3. Hasil Validasi Ahli Materi}

\begin{tabular}{|c|c|c|c|}
\hline No & Aspek & Indikator & $\begin{array}{c}\text { Skor } \\
\text { Validasi }\end{array}$ \\
\hline & Format LKPD & $\begin{array}{l}\text { Format LKPD disajikan sesuai dengan standar } \\
\text { format LKPD yang dijelaskan dalam proposal } \\
\text { penelitian }\end{array}$ & 5 \\
\hline \multicolumn{4}{|c|}{ Jumlah: $100 \%$} \\
\hline \multirow[t]{2}{*}{2.} & $\begin{array}{l}\text { Kesesuaian LKPD } \\
\text { dengan KI, KD, dan } \\
\text { Tujuan Pembelajaran }\end{array}$ & $\begin{array}{l}\text { a. Materi yang disajikan dalam LKPD sesuai } \\
\text { dengan yang terkandung dalam KI, KD, tujuan } \\
\text { pembelajaran serta Indikator Pencapaian } \\
\text { Kompetensi pembelajaran }\end{array}$ & 5 \\
\hline & & b. Materi yang disajikan sesuai dengan isi silabus & 4 \\
\hline \multicolumn{4}{|c|}{ Jumlah: $90 \%$} \\
\hline 3. & $\begin{array}{ll}\text { Kesesuaian } & \text { LKPD } \\
\text { dengan } & \text { Model } \\
\text { Pembelajaran } & \\
\end{array}$ & $\begin{array}{l}\text { LKPD disajikan sesuai dengan model pembelajaran } \\
\text { yang akan diterapkan (model problem based learning) }\end{array}$ & 4 \\
\hline \multicolumn{4}{|c|}{ Jumlah: $80 \%$} \\
\hline & $\begin{array}{ll}\text { Kesesuaian } & \text { LKPD } \\
\text { dengan RPP } & \\
\end{array}$ & $\begin{array}{l}\text { LKPD disajikan sesuai dengan runtutan kegiatan } \\
\text { pembelajaran yang terdapat dalam RPP }\end{array}$ & 4 \\
\hline
\end{tabular}

Sumber: Data primer2020

Berdasarkan hasil validasi materi oleh pakar, pada aspek format LKPD yang memiliki 1 indikator mendapat rata-rata 5 dengan nilai validasi $100 \%$, sedangkan pada aspek kesesuaian LKPD dengan KI, KD, dan tujuan pembelajaran yang memiliki 2 indikator mendapat rata-rata 4,5 dengan nilai validasi 90\%. Pada aspek ke 3 yaitu aspek kesesuaian LKPD dengan model pembelajaran yang memiliki 1 indikator mendapat rata-rata 4 dengan nilai validasi $80 \%$, dan pada aspek kesesuaian LKPD dengan RPP yang memiliki 1 indikator mendapat rata-rata 4 dengan nilai validasi $80 \%$. Secara keseluruhan aspek materi dari validator mendapat rata-rata 4,37 dengan nilai validasi $87,5 \%$ yang artinya berada pada kriteria "sangat baik".

\section{Validasi Partikalitas Siswa}

Pada tahap ini validasi partikalitas LKPD oleh peserta didik kelas XI IPS 3 SMA Negeri 1 Payakumbuh yang berjumlah 33 orang. Hasil validasi angket partikalitas LKPD yang peneliti kembangkan berdasarkan hasil instrumen validasi yang telah ditelaah oleh pakar adalah sebagi berikut: 
Tabel 4. Hasil Partikalitas Siswa

\begin{tabular}{llllll}
\hline No. & Aspek Yang Dinilai & Item & Rata-rata & Persentase & Keterangan \\
\hline 1. & Tampilan LKPD & 1 & 4,0 & $80 \%$ & Baik \\
\hline 2. & $\begin{array}{l}\text { Keterstrukturan } \\
\text { LKPD }\end{array}$ & 1 & 3,7 & $75,15 \%$ & Baik \\
\hline 3. & Memudahkan PBM & 1 & 3,9 & $78,18 \%$ & Baik \\
\hline $\mathbf{4 .}$ & $\begin{array}{l}\text { Keefektifitasan } \\
\text { Waktu }\end{array}$ & 1 & 4,03 & $81 \%$ & Sangat Baik \\
\hline $\begin{array}{l}\text { 5. } \\
\text { Meningkatkan } \\
\text { berpikir kritis }\end{array}$ & 1 & 3,6 & $72,12 \%$ & Baik \\
\hline Jumlah & $\mathbf{5}$ & $\mathbf{3 , 8 4}$ & $\mathbf{7 2 , 2 1 \%}$ & Baik \\
\hline Sumber: Data Primer2020 & & & &
\end{tabular}

Berdasarkan hasil partikalitas peserta didik, pada aspek tampilan LKPD yang memiliki 1 indikator mendapat rata-rata 4,0 dengan nilai validasi $80 \%$, sedangkan pada aspek keterstrukturan LKPD yang memiliki 1 indikator mendapat rata-rata 3,7 dengan nilai validasi $75,15 \%$, aspek ke 3 yaitu aspek memudahkan proses belajar mengajar yang memiliki 1 indikator mendapat rata-rata 3,9 dengan nilai validasi 78,18\%. Aspek ke 4 yaitu aspek keefektifitasan waktu yang memiliki 1 indikator mendapat rata-rata 4,03 dengan nilai validasi 81\%, sedangkan pada aspek meningkatkan berpikir kritis yang memiliki 1 indikator mendapatkan rata-rata 3,6 dengan nilai validasi $72,12 \%$. Secara keseluruhan aspek partikalitas peserta didik mendapat ratarata 3,84 dengan nilai validasi $72,21 \%$ yang artinya berada pada kriteria "baik".

\section{Uji efektivtas}

Uji efektivitas produk dilaksanakan pada kelas XI IPS 3 SMA N 1 Payakumbuh. Karena menggunakan desain eksperimen one group pretest and posttest maka uji coba produk dilakukan hanya pada satu kelas saja. Berdasarkan hasil uji efektivitas $t$ hitung sebesar 19,40 dan $t$ tabel dengan $\mathrm{df}=\mathrm{N}-1$ atau 33-1 $=32$ dengan $\alpha=0,05$ maka $\mathrm{t}$ tabel 2,036 sehingga $\mathrm{t}$ hitung $>$ dari $\mathrm{t}$ tabel. Artinya terdapat perbedaan yang signifikan antara hasil pre test dan post test siswa sebelum menggunakan LKPD dan setelah menggunakan LKPD pada materi integrasi sosial. Kesimpulan penelitian ini adalah LKPD yang dikembangkan pada pembelajaran sosiologi valid, praktis dan efektif serta berpengaruh terhadap kemampuan berpikir kritis peserta didik terhadap materi integrasi sosial.

\section{Pembahasan}

Pengembangan media LKPD pada pembelajaran Sosiologi khususnya materi integrasi sosial dapat memberikan warna baru bagi siswa dalam meningkatkan kemampuan berpikir kritis pada materi integrasi sosial. Hal ini berkaitan dengan penelitian yang dikemukakan oleh Muhamad Fathurohman (Fathurohman, 2017) yang mengungkapkan bahwa bahan ajar LKPD IPA berbasis pendekatan kontekstual dinyatakan layak dan dapat meningkatkan kemampuan berpikir analisis siswa. Pendapat ini juga berkaitan dengan penelitian (Fatimah, 2017) yang berjudul "Pengembangan Bahan Ajar Lembar Kegiatan Peserta Didik (LKPD) dapat Berbasis Inquiri Science Issues untuk Mengembangkan Critical Thinking Skills dan Curiosity Peserta Didik SMP" yang mengatakan bahwa perkembangan critical thingking skills peserta didik setelah menggunakan LKPD berdasarakan lembar observasi memiliki kategori cukup dan hasil gain score ternormalisasi memperoleh kategori sedang.

\section{Kesimpulan}

Media LKPD yang dikembangkan dinyatakan layak digunakan untuk meningkatkan kemampuan berpikir kritis siswa pada materi integrasi sosial pada pembelajaran Sosiologi kelas 
XI. Berdasarkan hasil validasi ahli media, media LKPD integrasi sosial memenuhi kriteria kelayakan "cukup baik/cukup layak", sedangkan berdasarkan hasil validasi ahli materi, media LKPD integrasi sosial memenuhi kriteria kelayakan "sangat baik/ sangat layak". Berdasarkan hasil uji partikalitas angket peserta didik, media LKPD integrasi sosial memenuhi kriteria kelayakan "baik/layak". Hasil uji-t independen menunjukkan bahwa terdapat perbedaan pemahaman peserta didik sebelum dan sesudah menggunakan media LKPD dalam pembelajaran integrasi sosial, dengan nilai signifikansi $(\mathrm{p})<0,05$ yaitu sebesar 0,000 . dengan nilai thitung sebesar 19,40 dan ttabel dengan $\mathrm{df}=\mathrm{N}-1$ atau 33-1 $=32$ dengan $\alpha$ 0,05 maka $\mathrm{t}$ tabel 2,036 sehingga $t$ hitung $>$ dari t tabel.

\section{Daftar Pustaka}

Craig, C. J., \& Orland-Barak, L. (2015). International Teacher Education: Promising Pedagogies Introduction', International Teacher Education: Promising Pedagogies (Part B) (Advances in Research on Teaching, Volume 22B) (pp. 1-5). Emerald Group Publishing Limited.

Fathurohman. (2017). Pengembangan Bahan Ajar LKPD IPA Berbasis Pendekatan Kontekstual Guna Meningkatkan Kemampuan Berpikir Analisis Peserta Didik. Skripsi. Universitas Negeri Yogyakarta.

Fatimah, F., Nurohman, S., \& Setianingsih, W. (2017). Pengembangan Bahan Ajar Lembar Kegiatan Peserta Didik (LKPD Berbasis Inquiry Science Issues Untuk Mengembangkan Critical Thinking Skills dan Curiosity Peserta Didik SMP. Skripsi. Universitas Negeri Yogyakarta.

Ibrhim, I. (2013). Deskripsi Implementasi Kurikulum 2013 Dalam Proses Pembelajaran Matematika di SMA Negeri 3 Maros Kabupaten Maros. Daya Matematis: Jurnal Inovasi Pendidikan Matematika, 3(3), 370-378.

Nurhayati. (2014). Peningkatan Kemampuan Berpikir Kritis Siswa Dalam Pembelajaran IPS Melalui Pendekatan SAVI Model Pembelajaran Berbasis Masalah Kelas VIII SMP Negeri 3 Godean. Skripsi. Universitas Negeri Yogyakarta.

Prastowo, P. (2014). Menyusun Rencana Pelaksanaan Pembelajaran Tematik Terpadu. Jakarta: Kencana.

Purwanto, P. (2007). Psikologi Pendidikan. Bandung: Alfabeta.

Rumini, R. (1998). Psikologi Umum. Yogyakarta: Kanisius.

Sadirman, S. (1996). Interaksi dan Motivasi Belajar Mengajar. Jakarta: Kencana.

Sari, Y. (2011). Analisis Faktor-faktor Yang Mempengaruhi Keberhasilan Usaha Pedagang Kaki Lima di GALABO (Gladag Langen Bogan) Solo Tahun 2011. Skripsi. Universitas Negeri Surakarta.

Sugiyono, S. (2009). Metode Penelitian Kuantitatif, Kualitatif, Dan R\&D. Bandung: Alfabeta.

Sukmadinata, S. (2005). Metode Penelitian Pendidikan. Bandung: Alfabeta.

Sylvia, I., Anwar, S., Khairani, K. (2019). Pengembangan Instrumen Penilaian Autentik Berbasis Pendekatan Authentic Inquiry Learning pada Mata Pelajaran Sosiologi di Sekolah Menengah Atas. Socius, 6(2), 103-120.

Thiagarajan, T. (1774). Elt in Asia The Digital Era: Global Citizenship and Identity. London: Routlodge.

Trianto, T. (2009). Mendesain Model Pembelajaran Inovatif Progresif. Jakarta: Kencana.

Widyantini, T. (2013). Penyusunan Lembar Kegiatan Siswa (LKS) sebagai Bahan Ajar. Pusat Pengembangan dan Pemberdayaan Pendidik dan Tenaga Kependidikan (PPPPTK) Matematika. Yogyakarta: PPPPTK Matematika.

Wulandari, B., \& Surjono, H. D. (2013). Pengaruh Problem-Based Learning Terhadap Hasil Belajar Ditinjau Dari Motivasi Belajar PLC Di SMK. Jurnal Pendidikan Vokasi, 3(2), 1-10 